\title{
Estudo de caso da conceção e aplicação de um jogo educativo
}

\author{
Carlos António Bertoncelli Júnior ${ }^{\text {b }}$, Rui Pedro Lopes ${ }^{b}$, Jorge Aikes Júnior ${ }^{a}$ \\ ${ }^{a}$ Universidade Tecnológica Federal do Paraná, Medianeira, Brasil, ${ }^{b}$ Centro de Investigação em \\ Digitalização e Robótica Industrial, Instituto Politécnico de Bragança, Portugal.
}

\section{Resumo}

A importância da implementação de metodologias pedagógicas ativas tem aumentado, especialmente na área do ensino superior. Estas metodologias estimulam o envolvimento do estudante diretamente no processo de aprendizagem em todos os estágios do planeamento, design, execução e avaliação, proporcionando-lhes a oportunidade de falar e ouvir, ler, escrever e refletir individualmente e em grupos, desenvolvendo, simultaneamente, o conteúdo curricular e as competências transversais, por meio de exercícios de resolução de problemas, pequenos grupos informais, simulações, estudos de caso, role-play e outras atividades. A utilização de jogos proporcionam essas características, com a expectativa de uma maior motivação na aprendizagem, mais eficiente e autónoma.

O trabalho apresentado neste artigo descreve o desenvolvimento e aplicação de um jogo educativo, atualmente em uso como uma experiência de aprendizagem na unidade curricular de Gestão de Sistemas e de Redes de um curso de Engenharia Informática. O jogo é do tipo estratégia, inicialmente desenvolvido como jogo de tabuleiro, estando a ser adaptado para dispositivos móveis utilizando Unreal Engine 4. O jogo simula um datacenter, onde o objetivo principal é permitir aos estudantes realizar decisões em um ambiente com recursos limitados, gerindo os recursos da melhor maneira possível. Esse jogo coloca dois alunos em competição e estimulando o desafio e a aprendizagem. O aluno que conseguir ocupar o espaço no datacenter, que conseguir acumular mais servidores e instalar mais serviços de rede, ganha.

O impacto do jogo está a ser avaliado recorrendo a dois instrumentos principais: observação direta, analisando interações entre jogo-jogador e jogador-jogador, e também por meio de questionário, utilizado para recolher dados sobre a satisfação dos alunos e contributo no processo de aprendizagem. 
Palavras-chave: game-based learning, gamificação, metodologias pedagógicas ativas.

\section{Introdução}

A palavra Gamificação tem vindo a ser usada em vários contextos e com bastante frequência. $\mathrm{O}$ ato de Gamificar refere-se à utilização de elementos, mecânicas e características de jogos em tarefas ou ações que não sejam jogos (Dichev \& Dicheva, 2017). Para que um jogo possa cativar seu público deverá ter formas de recompensar seu jogador, algum tipo de reforço e um sistema de feedback focado em melhorar o envolvimento afim de tornar o jogo ainda mais atrativo (Zichermann \& Cunningham, 2011).

Atividades de aprendizagem que permitam o envolvimento pessoal do indivíduo com o meio, baixa pressão e flexibilidade de aprendizagem garantem que se, dada liberdade de escolha, tornar a atividade mais atrativa para os indivíduos que a exercem, ainda que, em ambiente escolar, se desenvolva uma competição saudável entre os indivíduos em busca do melhor desempenho (Machado, Rufini, Maciel, \& Bzuneck, 2012).

$\mathrm{Na}$ área da educação e ensino, técnicas de Gamificação já foram usadas algumas vezes para melhorar a motivação e engajamento dos indivíduos. Apesar de ser uma área atualmente em desenvolvimento, que necessita de mais estudos para definir as melhores maneiras de gamificar certas atividades, já são conhecidas algumas dificuldades, por exemplo, a necessidade de abordagens distintas para gamificar atividades, trabalhos em grupo e outros elementos de interação em sala de aula (Dichev \& Dicheva, 2017). Este ainda é um campo recente e que precisa ser estudado em diversos contextos. A objetividade de tornar o processo de ensino gamificado é fazer com que o estudante procure o conhecimento por si só dentro de um ambiente competitivo afim de melhorar seu desempenho e prepará-lo para o mercado de trabalho.

No decorrer dos anos, o processo de aprendizagem foi constantemente adaptado à realidade dos indivíduos com o intuito de estimular a motivação e o engajamento. A utilização de metodologias de ensino ativas e mais participativas beneficiam os estudantes, fazendo com que a interação durante uma aula, por exemplo, não dependa somente do professor mas que inclua contributos dos colegas para o desenvolvimento geral (Campbell et al., 1993). A utilização de jogos em sala de aula tem-se mostrado uma maneira eficiente de proporcionar cenários desafiadores onde o aluno passa a lidar com a consequência de suas ações e também a ser recompensado por elas. 


\section{Conceitos}

O termo paradigma foi inicialmente utilizado com o intuito de designar um exemplo em relação a algo. Pode ser utilizado também para determinar as características dentro de um periodo histórico. Atualmente é utilizado pela maioria dos autores de forma a conceituar um processo ou padrão que possua um certo embasamento teórico, metodologia sólida e amplamente aceita (Behrens \& Lopes, 2014).

A pedagogia pode ser definida como um conjunto de práticas e técnicas com o objetivo de tornar o método de ensino-aprendizagem mais eficiente para as pessoas envolvidas no processo. A área pedagógica possui uma abrangência que vai além da disposição dos métodos de ensino em sala de aula, contempla também a disposição do ambiente escolar como um todo e busca encontrar as melhores metodologias de ensino para que o processo de aprendizado se torne mais eficiente e adequado para o maior número de estudantes possível (Amélia \& Franco, 2015).

As metodologias de ensino têm, por objetivo, buscar formas eficientes e motivadoras que contribuam para para o processo de aprendizagem dos alunos. É uma das muitas áreas que pertencem a pedagogia e geralmente são desenvolvidas por pedagogos que buscam encontrar os melhores métodos e técnicas no contexto de ensino em que se encontram (Huang, Malicky, \& Lord, 2006).

O desenvolvimento de cada metodologia deve levar em consideração as necessidades do estudante, bem como suas limitações e qualidades. As diferentes estratégias de ensino podem levar a resultados bons ou ruins, dependendo do perfil do estudante e das características do mesmo, que podem ser exibidas no decorrer do processo de aprendizagem. Isso ainda levando em consideração que a singularidade de cada indivíduo pode afetar o progresso no decorrer da aprendizagem, além de que o ambiente social que o mesmo se encontra pode influenciar de maneira direta (Nagem, Carvalhaes, \& Dias, 2001).

A partir do momento que o foco é a aprendizagem, o papel do professor em sala de aula deixa de ser o indivíduo que expõe o conteúdo, mas passa a ser o responsável por ajudar o aluno na construção do seu conhecimento (Borges \& Alencar, 2014). Adicionalmente, com o contributo adicional de adequar a preparação dos estudantes ao mercado de trabalho, as competências profissionais atualmente vêm exigindo um senso crítico e perfil pró-ativo (Borges \& Alencar, 2014). Para que estas qualidades possam ser despertadas no estudante é necessário que as práticas pedagógicas em sala de aula propiciem a discussões, pesquisas, superação de desafios e a resolução de problemas (Borges \& Alencar, 2014). 


\section{Aprendizado baseado em jogos}

O aprendizado baseado em jogos trata-se de uma subárea da gamificação, que tem como foco único a otimização do ensino por meio da utilização de jogos e seus aspectos. Por definição a palavra Gamificação consiste no ato de usar elementos de jogos em outras atividades afim de motivar as pessoas a atingirem determinados objetivos. Os elementos a serem inseridos podem ser desafios, recompensas, pontos, entre outros, com base em regras que definem as diretrizes da atividade. Um dos principais objetivos em gamificar uma determinada atividade é aumentar os níveis de engajamento para estimular a motivação de maneira intrínseca e extrínseca. A Gamificação pode fazer uso também de ambientes simulados e lúdicos com o intuito de tornar a atividade muito mais atrativa (Busarello, 2016).

A área de jogos está em constante crescimento e muito vem sendo estudado a respeito dos benefícios que eles proporcionam aos jogadores. Com base nisso diversas empresas começaram a tentar gamificar suas atividades. As empresas buscam gamificar suas operações para que a motivação e o engajamento passem a se tornar parte do dia-a-dia, melhorando a produção e o trabalho em equipe de seus funcionários (Castro, 2016).

Diversos estudos acerca da Gamificação na educação vêm sido realizados para tornar o processo de ensino mais eficiente e motivante (Fallis, 2013). A motivação no ambiente escolar é um dos principais fatores que garante o resultado desejado. A utilização de elementos de jogos na educação proporcionam suporte ao aprendizado em diferentes atividades e contextos (Dichev \& Dicheva, 2017; Pedro Lopes, 2016).

As mecânicas consistem no conjuntos de regras e condições para alcançar o objetivo desejado. Também são responsáveis por definir como será o tipo de jogo, a visão do mesmo, como será a jogabilidade de uma maneira geral (Schell, 2008). A mecânica de jogo é definida como uma etapa que consiste de sete elementos principais responsáveis por determinar como será o decorrer do jogo, sendo elas: missões/desafios, ranking, medalhas/troféus, níveis, pontos, ambientação/integração, ciclos de engajamento. 


\section{Desenvolvimento}

Utilizando técnicas de gamificação e aprendizado baseado em jogos foi desenvolvido um jogo por turnos que possui como objetivo ajudar na aprendizagem de conceitos de gerenciamento e layout de um data center. O desenvolvimento do Cabinet foi iniciado após a definição dos elementos de game design no qual o jogo iria herdar de sua versão analógica. Como grande parte dos elementos foram mantidos e já possuindo um game design consolidado, foi possível então focar no desenvolvimento dos elementos gráficos, sonoros e mecânicos do jogo. Como motor gráfico e multiplataforma foi escolhido a Unreal Engine, pela sua flexibilidade no desenvolvimento e recursos gráficos capazes de proporcionar uma ótima experiência aos usuários.

Uma das primeiras etapas do desenvolvimento foi definir como seriam realizadas as interações entre jogador-jogador. A princípio a ideia era fazer com que toda a partida acontecesse com somente um dispositivo, de forma a que os jogadores realizassem as jogadas de maneira intercalada. Entretanto, pensou-se em utilizar as funcionalidades que a Unreal Engine proporciona, para não só permitir que cada aluno pudesse jogar em seu dispositivo, mas também em rede local e por meio da internet.

As regras do jogo seguiram os princípios da sua versão analógica e, por se tratar de um jogo de turnos digital, foram realizados alguns ajustes com o objetivo de tornar a experiência mais agradável aos alunos. No início de cada partida é definido o jogador que iniciará o turno com base na ordem de conxão da partida, portanto, o segundo jogador a se conectar será o segundo jogador a jogar no primeiro turno. O jogo divide-se em 2 fases: a fase de coleta dos recursos e a fase de compra/instalação de equipamentos. Na primeira fase, os jogadores escolhem os recursos que desejam coletar na rodada, sendo que um recurso já selecionado não pode voltar a ser escolhido até o final da rodada atual. Cada jogador possui um trabalhador, de forma que cada um possa realizar a coleta de até três recursos. Ao escolher o recurso desejado, o jogador recebe instantaneamente o mesmo. Ao final da etapa de coleta, os jogadores entram na fase de compra, onde escolherão como irão gastar os recursos coletados, podendo ser por meio da aquisição de novos racks, aquisição de novos servidores ou serviços.

Cada rack possui espaço físico para receber três servidores e, até o final da partida, podem ser adquiridos somente dois racks. Cada rack adquirido já acompanha uma Power Supply Unit com o objetivo de suprir a necessidade energética dos servidores (Fig. 1). 


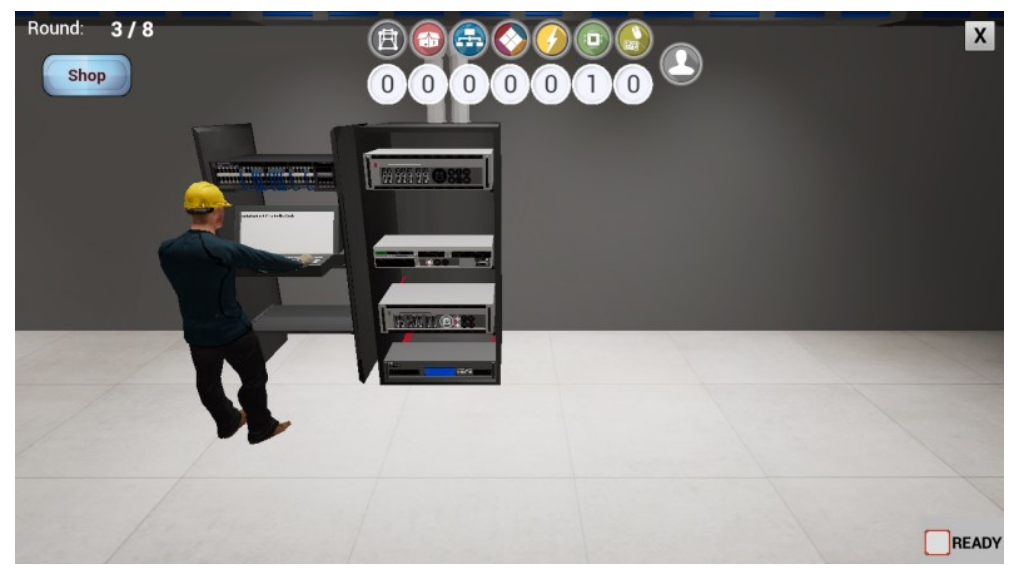

Fig. 1 Visão do data-center.

Além de ser possível jogar partidas multijogador, foi desenvolvido uma inteligência artificial para permitir que o aluno possar jogar partidas sem necessidade de uma conexão com a internet. Essa inteligência artificial foi desenvolvida utilizando uma estrutura de decisão denominada behaviour tree. Cada decisão realizada pelo agente é feita com base nos elementos presentes no ambiente, análise das escolhas do adversário e gerenciamento dos recursos que o agente possui.

A modelagem dos personagens, objetos presentes e animações contidas nas cenas foram criadas utilizando Blender, uma ferramenta open source de modelagem e animação 3D (Fig. 2).

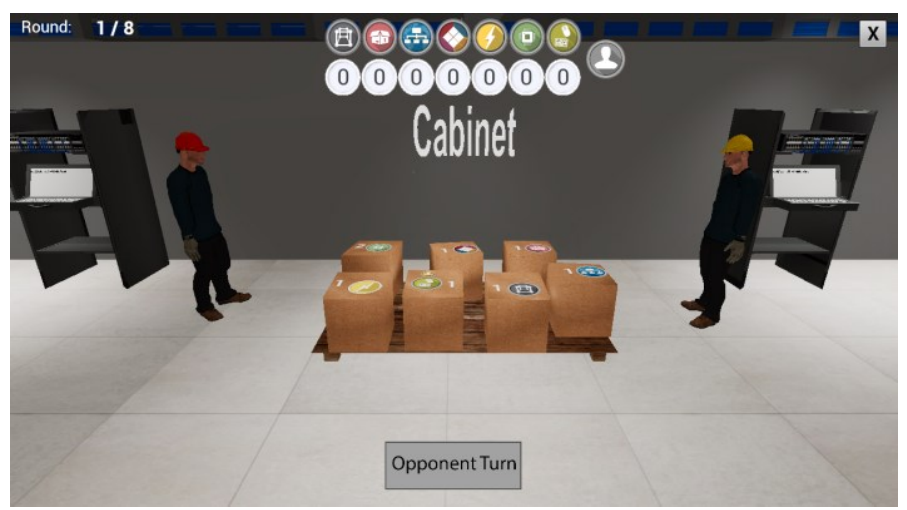

Fig. 2 Visão geral do cenário. 


\section{Discussões e Resultados}

Foi realizada uma aplicação em sala de aula com o objetivo de analisar as interações entre jogo-jogador e jogador-jogador com a intenção de avaliar questões de design e usabilidade para melhorar a experiência dos alunos. Ao longo da aplicação, 23 alunos jogaram a versão digital do jogo Cabinet e 8 alunos jogaram a versão analógica. As aplicações foram realizadas em duas turmas das disciplinas de Gestão de Sistemas e de Redes, do curso de Engenharia Informática do Instituto Politécnico de Bragança.

Antes de iniciar sua primeira partida, os alunos que jogaram a versão digital do Cabinet foram orientados a seguir um breve tutorial contido dentro do jogo, que explica as mecânicas envolvidas ao longo dos turnos e algumas dicas que podem ser fundamentais para auxiliar na vitória. Já os alunos que jogaram a versão analógica do Cabinet, contaram com um livro de regras para servir de base e orientação ao longo da partida.

Durante a aplicação do jogo Cabinet, um dos fatores mais analisados foi a interação entre os alunos. Por se tratar de um jogo que coloca ambos os alunos em um cenário competitivo, onde cada um tem que buscar construir o melhor data-center com uma quantidade de turnos pré-determinada e os recursos que são coletados ao longo dos mesmos, o jogo foi capaz de causar euforia e comoção dos jogadores em busca da vitória. Mesmo aqueles que acabavam por perder, buscavam jogar novamente contra os mesmos adversários com o objetivo de supera-los.

Houve uma melhoria notável no desempenho dos alunos ao longo das partidas, pois no início cada jogador ainda não está habituado com as mecânicas e uso dos recursos. Entretanto, assim que eles passam a perceber a importância de cada tipo de recurso, a competitividade entre os alunos aumenta. Isso é notável no momento em que eles passam a coletar os recursos não somente para uso próprio, mas muitas vezes para evitar que seu adversário obtenha vantagem ou mesmo o monopólio de algum recurso de hardware ou software que pode ser primordial para garantir a vitória.

Após a aplicação do Cabinet os alunos responderam um questionário que serviu de base para avaliação e melhoramento de algumas características presentes no Cabinet versão digital. Com os resultados obtidos foi possível tirar diversas conclusões acerca das mecânicas, jogabilidade e características presentes no jogo (Fig. 3). 


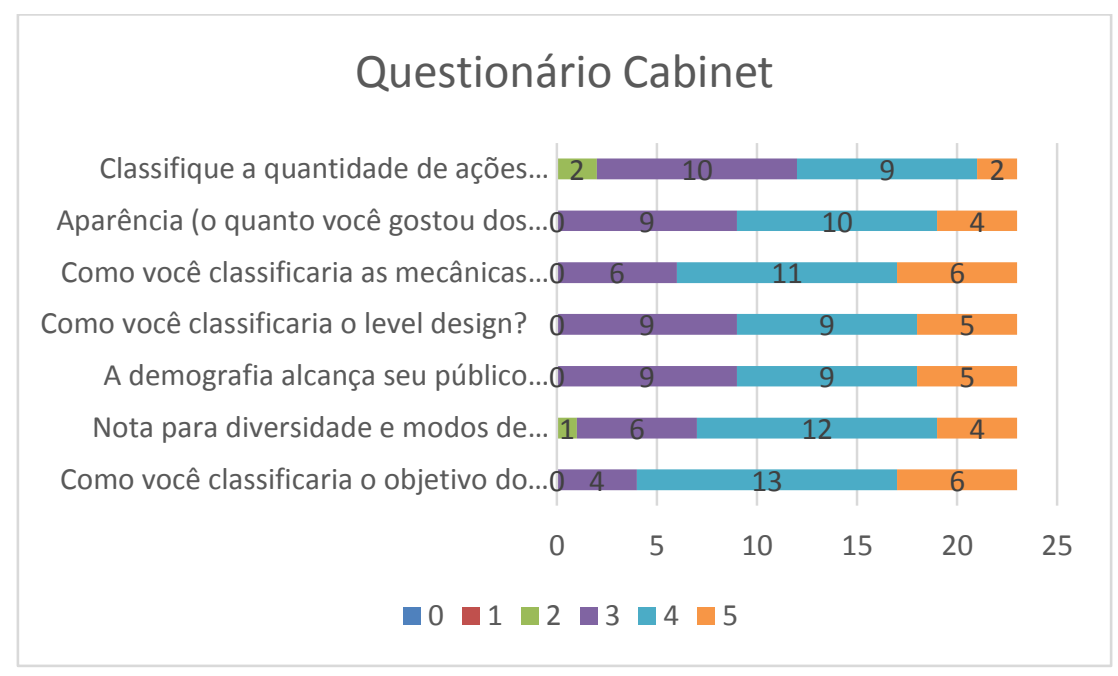

Fig 3. Respostas do questionário sobre a aplicação do jogo Cabinet.

Fica evidente de que a quantidade de ações disponíveis, segundo o ponto de vista dos jogadores, é suficiente tendendo a muitas. Atribuímos esse resultado obtido às diversas possibilidades de combinações e versatilidade disponível para o usuário, que pode optar por realizar a instalação dos tipos de servidor que quiser, seguindo sua própria abordagem afim de garantir a maior quantidade de pontos possível.

Além do questionário aplicado, foi realizado a filmagem das telas, que permitiram realizar uma análise mais aprofundada das interações jogador-jogo com o objetivo de melhorar aspectos da interface gráfica e identificar dificuldades encontradas pelos alunos.

Por meio da análise por observação da interação jogador-jogo pudemos notar que os alunos que optaram por iniciar uma partida sem seguir o tutorial inicial recomendado no início da aplicação, foram os que mais levaram tempo até concluir suas partidas, pois além de não entender completamente como o jogo funcionava, acabavam por não conseguir decidir com clareza as melhores ações a serem tomadas.

Um fator interessante observado na análise da interação entre jogador-jogo foi que os jogadores que realizaram o tutorial no início da aplicação, em sua maioria, foram os que tiveram a vitória com o menor número de partidas jogadas. Por meio da Fig. 4 pode-se ter uma noção sobre a quantidade de partidas que a amostra de alunos necessitou até conseguir sua primeira vitória. 


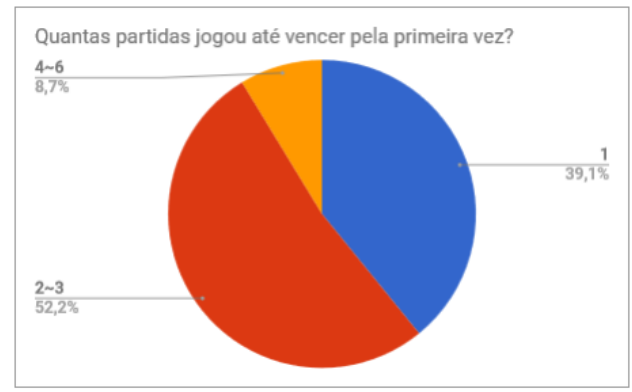

Fig. 4 Quantidade de partidas até alcançar a primeira vitória.

\section{Conclusão}

Jogos digitais são jogados pela grande maioria dos jovens, apesar de que esses jogos não costumam ser focados essencialmente na educação. Entretanto, a maior parte dos jogos consegue despertar a motivação no seu público alvo e também acabam por contribuir com a aprendizagem de maneira indireta. Jogos vêm sendo utilizados de maneira cada vez mais frequente em práticas pedagógicas ativas de ensino como uma ferramenta de auxílio ao aprendizado principalmente pelo aspecto dinâmico que eles possuem, enredo e mecânicas que envolvem o jogador e o coloca como protagonista e responsável pelo desfecho do jogo, motivando-oe prendendo sua atenção.

Uma análise qualitativa realizada por meio das observações e entrevistas sugere que o entendimento dos elementos presentes no jogo e a velocidade das interações entre jogojogador e jogador-jogador podem variar com base no estilo de cada jogador e na sua facilidade de aprendizado e adaptação ao ambiente do jogo.

Além do propósito de ajudar a aprender, o Cabinet ainda faz com que os alunos interajam entre si e se divirtam realizando algo que pertence ao escopo da disciplina e tornará a experiência de estudo deles mais agradável. Cabinet não se trata apenas de um jogo, mas de uma maneira diferenciada e dinâmica de ensinar elementos que pertençam a disciplina de Gestão de Sistemas e de Redes.

A área da educação está em constante evolução e cada vez mais tenta buscar a inovação nas práticas de ensino, seja utilizando novas tecnologias ou por meio de melhoramentos em técnicas já consolidadas. Apesar das inúmeras adversidades e fatores que muitas vezes acabam por distrair ou desmotivar os alunos, novas metodologias e técnicas de engajamento proporcionam maneiras diferenciadas e dinâmicas de fazer com que o aluno participe em sala de aula e sinta-se motivado a aprender. 


\section{Referências}

Amélia, M., \& Franco, S. (2015). Práticas pedagógicas de ensinar-aprender : por entre resistências e resignações, 601-614.

Behrens, M. A., \& Lopes, A. R. R. (2014). Ação docente no ensino superior: reflexões sobre paradigmas educacionais inovadores na prática pedagógica, 1-16.

Borges, T. S., \& Alencar, G. (2014). Metodologias ativas na promoção da formação crítica do estudante: o uso das metodologias ativas como recurso didático na formação crítica do estudante do ensino superior. Cairu Em Revista, 3(4), 119-143.

Busarello, R. I. (2016). Gamification Principios e Estrategias.

Campbell, R., Okey, J., Quitadamo, I. J., Kurtz, M. J., Paul, R. and Nosich, G., \& Rathburn, B. S. (1993). Curriculum \& Leadership Journal_ Skills for the 21st Century_teaching higher-order thinking. CBE - Life Sciences Education, 6, 1-15.

Castro, F. S. de. (2016). A gamification framework as a collaboration motivator for software development teams.

Dichev, C., \& Dicheva, D. (2017). Gamifying education: what is known, what is believed and what remains uncertain: a critical review. International Journal of Educational Technology in Higher Education (Vol. 14). International Journal of Educational Technology in Higher Education.

Fallis, A. . (2013). Gamificação Nas Práticas Pedagógicas: Um Desafio Para a Formação De Professores Em Tempos De Cibercultura. Journal of Chemical Information and Modeling, 53(9), $1689-1699$.

Huang, M., Malicky, D., \& Lord, S. (2006). Choosing an optimal pedagogy: A design approach. Proceedings - Frontiers in Education Conference, FIE, 1-6.

Machado, A. C. T. A., Rufini, S. É., Maciel, A. G., \& Bzuneck, J. A. (2012). Estilos motivacionais de professores: preferência por controle ou por autonomia. Psicologia: Ciência e Profissão, 32(1), 188-201.

Nagem, R. L., Carvalhaes, D. D. O., \& Dias, J. (2001). Uma proposta de metodologia de ensino com analogias. Revista Portuguesa de Educação, 14(1), 197-213.

Pedro Lopes, R. (2016). Gamification As a Learning Tool. International Journal of Developmental and Educational Psychology. Revista INFAD de Psicología., 2(1), 565. https://doi.org/10.17060/ijodaep.2014.n1.v2.473

Schell, J. (2008). The art of game design. The effects of brief mindfulness intervention on acute pain experience: An examination of individual difference (Vol. 1).

Zichermann, G., \& Cunningham, C. (2011). Gamification By Design. Vasa. 